\title{
Clinical diagnosis: a post-mortem assessment of accuracy in the 1980s
}

\author{
Jane Mercer and I.C. Talbot \\ Royal Infirmary, Leicester, P.O. Box 65, Leicester LE2 7LX, UK.
}

\begin{abstract}
Summary: The clinical diagnoses of a series of $\mathbf{4 0 0}$ patients dying in hospital were compared with the pathological findings at autopsy. The clinical diagnoses were precisely confirmed in only $\mathbf{4 6 . 7 5 \%}$ of cases (average age $65.3 \mathrm{y}$ ). Potentially treatable disease was missed in $13 \%$ of patients (average age $72.7 \mathrm{y}$ ). The most frequent errors, both of under-diagnosis and over-diagnosis, were for pulmonary embolus, pneumonia and myocardial infarction. Over-diagnosis increased with length of hospital stay. Peritonitis and other deep-seated sepsis were surprisingly frequently missed in life. The findings closely parallel those from other units both in Britain and overseas, and suggest that there is currently a high diagnostic error rate, which varies remarkably little from one institution to another.
\end{abstract}

Introduction

Recent developments in medicine have resulted in greatly increased sophistication of both investigations and therapy. In parallel with this trend, the everincreasing cost of modern medical procedures has evoked demands from the medical and other professions for audit of clinical management.

The monitoring of clinical diagnosis is an essential element of medical audit, and the ultimate test of diagnostic accuracy is provided by the autopsy. However, during the period of recent development in 'high tech' medicine, there has been a dramatic decline in the number of hospital autopsies performed, other than for medico-legal purposes (Cameron, 1983). This is an international trend, noted not only in the United Kingdom, but also in the Federal Republic of Germany (Sandritter et al., 1980) and repeatedly in the United States (Robinson, 1983). Many reasons have been given for this decline, the majority of which point to a reduction in the esteem with which the autopsy is regarded (McGoogan \& Cameron, 1978).

Several investigators have shown that, even when diagnoses are often based on computed tomographic (CT) and isotope scanning, ultra-sound and ever more sophisticated biochemical investigations, a large proportion of clinical diagnoses are still incomplete or erroneous (Thurlbeck, 1981). Even in a prospective study, Cameron \& McGoogan (1981a) found that the

Correspondence: J. Mercer, M.B., Ch.B.

Accepted: 1 March 1985 diagnosis of the major cause of death was only correct in $61 \%$ of cases and 449 unanticipated diagnoses were discovered in 1,152 autopsies.

All of the above studies were undertaken in well established teaching hospitals. In order to determine whether a similar situation exists in a teaching hospital associated with the youngest medical school in the United Kingdom, we have performed an analysis of the clinical diagnoses and pathological findings in a series of patients who died in hospital and came to autopsy.

\section{Materials and methods}

Adequate clinical information was available for 400 out of $\mathbf{4 4 2}$ hospital autopsies (excluding coroner's post-mortems) performed on adults at the Leicester Royal Infirmary between January 1982 and May 1984. The clinical notes and a member of the clinical team looking after the patient were carefully consulted to form as comprehensive a picture as possible of the clinical diagnoses, including the clinical causes of death. These were correlated with the autopsy findings in 2 ways: firstly, actual agreements or disagreements between clinical and pathological diagnoses were recorded for ten major disease headings. The diseases chosen were considered to be the commoner lifethreatening conditions, namely; pulmonary embolus, pneumonia, malignant neoplasm, myocardial infarc-

The Fellowship of Postgraduate Medicine, 1985 
Table I Categories of clinical diagnostic error

\begin{tabular}{|c|c|c|}
\hline \multirow[b]{2}{*}{ Grade of clinical diagnostic error } & \multicolumn{2}{|c|}{ Examples } \\
\hline & Clinical diagnosis & Pathological diagnosis \\
\hline I Failure to diagnose a treatable disease & Carcinomatosis & Bronchopneumonia \\
\hline \multicolumn{3}{|l|}{ II Errors in identifying organ/system } \\
\hline (a) Misplaced diagnosis & Respiratory failure & Myocardial infarction \\
\hline (b) Under-diagnosis & $\begin{array}{l}\text { Chronic lymphatic } \\
\text { leukaemia (CLL) }\end{array}$ & $\begin{array}{l}\text { CLL, carcinoma of rectum } \\
\text { and liver metastases }\end{array}$ \\
\hline (c) Over-diagnosis & $\begin{array}{l}\text { Carcinoma of breast } \\
+ \text { gastrointestinal bleed }\end{array}$ & Carcinoma of breast \\
\hline $\begin{array}{l}\text { III Errors in identifying disease, but not } \\
\text { organ/system }\end{array}$ & $\begin{array}{l}\text { Mitral stenosis and } \\
\text { incompetence }\end{array}$ & Myocardial infarction \\
\hline IV Imprecise diagnosis & Carcinomatosis & $\begin{array}{l}\text { Carcinoma of bronchus } \\
\text { with metastases }\end{array}$ \\
\hline
\end{tabular}

tion, sepsis (septicaemia and/or deep-seated abscesses), peritonitis, cerebrovascular 'accidents' (including both intra-cranial haemorrhage and infarction), leaking or dissecting aortic aneurysms and intestinal strangulation or infarction. Only histologically confirmed pneumonia was included under the appropriate heading. Secondly, an assessment was made of the significance of each disagreement, using a graded classification, according to the likely effect on clinical outcome; I, failure to clinically diagnose a treatable disease was considered the most serious disagreement, followed by, in descending order of significance: II, errors in identifying the diseased organ or system, (a) misplaced diagnosis, (b) under-diagnosis, (c) overdiagnosis; III, errors in identifying the disease but not the organ or system; IV imprecise diagnosis. Typical examples of each of these categories are shown in Table I.

Category I included only cases in which a correct clinical diagnosis followed by appropriate treatment was likely to have altered the clinical outcome. In the example given in Table I, the clinical diagnosis of carcinomatosis was not confirmed at autopsy, and bronchopneumonia diagnosed at post-mortem was the main disease present. Failure to diagnose bronchopneumonia was not included in category I when it was secondary to, for example, bronchial carcinoma, as a terminal event and therefore unlikely to affect the patients prognosis regardless of treatment. Disease 8 missed clinically but unlikely to respond to treatmento for example, intracerebral haemorrhage, were als excluded from category $I$. The mean age of the patients and mean duration of stay in hospital for each category were analysed.

\section{Results}

Table II shows the agreements and also the disagreements for each of the ten major disease headings.

Table II Agreements and disagreements between clinical diagnosis and pathological findings for 10 major disease headings

\begin{tabular}{|c|c|c|c|}
\hline & $\begin{array}{l}\text { Clinical diagnosis not } \\
\text { found at autopsy } \\
\text { (Over-diagnosis) }\end{array}$ & $\begin{array}{c}\text { Clinical diagnosis } \\
\text { confirmed at autopsy } \\
\text { (Agreement) }\end{array}$ & $\begin{array}{c}\text { Disease first discovered } \\
\text { at autopsy } \\
\text { (Under-diagnosis) }\end{array}$ \\
\hline Pulmonary embolus & $12(43 \%)$ & 16 & $49(75 \%)$ \\
\hline Pneumonia & $24(26 \%)$ & 69 & $65(49 \%)$ \\
\hline Malignant neoplasm & $20(14 \%)$ & 124 & $11(8 \%)$ \\
\hline Myocardial infarction & $14(29 \%)$ & 35 & $16(31 \%)$ \\
\hline Sepsis & $2(13 \%)$ & 13 & $12(48 \%)$ \\
\hline Peritonitis & $0(0) \%$ & 12 & $13(52 \%)$ \\
\hline Cerebrovascular 'accident' & $3(9 \%)$ & 31 & $5(14 \%)$ \\
\hline $\begin{array}{l}\text { Gastrointestinal } \\
\text { haemorrhage }\end{array}$ & $9(24 \%)$ & 28 & $1(4 \%)$ \\
\hline $\begin{array}{l}\text { Leaking of dissecting } \\
\text { aortic aneurysm }\end{array}$ & $3(60 \%)$ & 2 & $9(82 \%)$ \\
\hline $\begin{array}{l}\text { Intestinal strangulation/ } \\
\text { infarction }\end{array}$ & $0 \quad(0 \%)$ & 9 & $7(44 \%)$ \\
\hline
\end{tabular}


Table III The age and duration of stay in hospital for cases in which clinical and pathological diagnosis were in agreement and for categories of disagreement

\begin{tabular}{lcccccc}
\hline Category & No. of & $\begin{array}{c}\text { Mean age } \\
\text { cases }\end{array}$ & $\begin{array}{c}\text { cases } \\
\text { cage }\end{array}$ & $\begin{array}{c}\text { Mean } \\
\text { range }\end{array}$ & $\begin{array}{c}\text { duration } \\
\text { of stay } \\
(d)\end{array}$ & $\begin{array}{c}\text { Range of } \\
\text { stay }(d)\end{array}$ \\
\hline Agreed & 187 & 46.75 & 65.3 & $15-94$ & 14 & $1-240$ \\
I & 52 & 13 & 72.7 & $35-91$ & -9.5 & $1-27$ \\
IIa & 44 & 11 & 74.3 & $50-93$ & 15 & $1-90$ \\
b & 14 & 3.5 & 73.6 & $55-93$ & 11 & $1-50$ \\
c & 6 & 1.5 & 69.2 & $52-88$ & 21 & $1-107$ \\
III & 38 & 9.5 & 66.7 & $31-89$ & 11 & $1-52$ \\
IV & 59 & 14.75 & 65.9 & $15-90$ & 18 & $1-150$ \\
\hline
\end{tabular}

Pneumonia and malignant neoplasms were the most frequent diseases encountered (134 and 135 cases, respectively), and pneumonia was most frequently clinically missed (in 65 out of 134 cases, 49\%), followed by pulmonary embolus (in 49 out of 65 cases, $75 \%$ ). Leaking or dissecting aortic aneurysm was missed in 9 of 11 cases ( $82 \%)$, peritonitis was missed in 13 out of 25 cases $(52 \%)$ and sepsis was missed in 12 out of 25 cases (48\%). Myocardial infarction was missed in 16 out of 51 cases $(31 \%)$ and was overdiagnosed in a further 14 cases in which no pathological evidence was found. In absolute terms, pneumonia, and proportionately, leaking or dissecting aortic aneurysm were the most frequently over-diagnosed diseases ( 24 cases and $60 \%$ respectively), but as many as $43 \%$ of pulmonary emboli diagnosed clinically were not found at autopsy.

There was complete agreement between the pathological and the clinical diagnoses in 187 of the 400 patients $(46.75 \%)$. The mean age of these patients was $65.3 \mathrm{y}$ (range 15-94 y) and the mean duration of stay in hospital was $40 \mathrm{~d}$ (range less than $1 \mathrm{~d}$ to 8 months).

The age and duration of stay in hospital for cases in which the clinical and pathological diagnoses were in agreement and for each category of disagreement are shown in Table III.

\section{Discussion}

In $53.25 \%$ of the cases in this study one or more of the clinical diagnoses were erroneous. This high incidence of diagnostic error may partly reflect the selection of cases which must inevitably result from a low postmortem rate $(16 \%$ of adult deaths during the period of this investigation, excluding coroner's cases), there being more likelihood of an autopsy being requested when the clinical diagnosis is in doubt. However, Cameron et al. (1980) showed in a larger study, that the level of clinical confidence in a diagnosis was not closely related to its accuracy.
Our results resemble those of previous studies, to a remarkable degree, with high levels of errors, particularly in the diagnosis of pulmonary embolism (Sandritter et al., 1980; Thurlbeck, 1981; Cameron \& McGoogan, 1981b; Britton, 1974) and pneumonia, (Thurlbeck, 1981; Britton, 1974). These are both common conditions, likely, at least, to contribute to a patient's death, and this type of diagnostic inaccuracy should cause some clinical concern. A mitigating factor here is that some emboli found at autopsy may have been too small to cause significant functional impairment. On the other hand, massive pulmonary embolism would often cause death too rapidly for certain diagnosis to be made.

The high rate of under-diagnosis for leaking or dissecting aortic aneurysms may also be due to the rapid downhill course in these patients. Our figure of $82 \%$ is much higher than that of Cameron \& McGoogan (46\%; 1981b), but our number of cases is too small to draw any valid conclusions from this. Potentially treatable conditions, such as peritonitis, sepsis and intestinal strangulation or infarction were rarely over-diagnosed, but were relatively frequently missed, our figures corresponding closely with those of previous workers (Britton, 1974; Cameron \& McGoogan, 1981b).

The $29 \%$ over-diagnosis of myocardial infarction compares with the figure of $23 \%$ found by Cameron \& McGoogan (1981b) and $26.4 \%$ by Sandritter et al. (1980). This must be a serious diagnostic discrepancy, even allowing for some degree of under-diagnosis by the pathologist of early lesions, which may show no gross abnormality.

The significance of these discrepancies is confirmed by the gradings in Table III. There was failure to diagnose a clinically treatable disease in $13 \%$ of autopsied cases in our series. This bears interesting comparison with a corresponding figure of $15 \%$ in the series of Cameron et al. (1980). The average age of our patients in this group was $72.7 \mathrm{y}$, significantly higher than in the group in which there was clinical and 
pathological agreement $(65.3 \mathrm{y})$. The relatively short average stay in hospital $(9.5 \mathrm{~d})$ for this category suggests that the terminal illness in these patients followed a more fulminant course. For all categories of disagreement the average age $(70.0 \mathrm{y})$ was relatively high, the oldest groups being those with a misplaced diagnosis or missed diagnosis (74.3 and $73.6 \mathrm{y}$, respectively). An increase in diagnostic discrepancies with age was also found by Cameron \& McGoogan (1981a). It is of interest that a high rate of overdiagnosis was related to a longer average stay in hospital (21 d).

Our confirmation of the findings of others elsewhere suggests that there is still generally room for improvement. Table II shows how frequently important diseases are clinically missed, and the findings at autopsy unexpected. It is the unexpected which, by definition, will continue to be clinically missed, however sophisticated modern diagnostic methods may become. Indeed, the more complex the diagnostic procedure, the more critical should clinicians become. For this reason, the autopsy examination still has an important place in monitoring patient care and the current decrease in the hospital post-mortem rate is difficult to justify. The objection that in modern times it is more difficult to obtain consent for autopsy lacks credibility when some clinicians do still manage to maintain a high autopsy rate of up to $80-90 \%$, against the general trend (Cameron, 1983) suggesting that, if

\section{References}

ALDERSON, M.R., BAYLISS. R.I.S., CLARKE, C.A. \& WHITFIELD, A.G.W. (1983). Death certification. Leading article. British Medical Journal, 287, 444.

BRITTON, M. (1974). Diagnostic errors discovered at autopsy. Acta Medica Scandinavica, 196, 203.

CAMERON, H.M. (1983). The autopsy - illusion and reality. Pathology Annual, 18 (2), 333.

CAMERON, H.M. \& MCGOOGAN, E. (1981a). A prospective study of 1152 hospital autopsies: I inaccuracies in death certification. Journal of Pathology, 133, 273.

CAMERON, H.M. \& McGOOGAN, E. (1981b). A prospective study of 1152 hospital autopsies: II analysis of inaccuracies in clinical diagnoses and their significance. Journal of Pathology, 133, 285. relatives are approached in an appropriate manner, it is still socially acceptable to habitually follow cases to post-mortem. A higher post-mortem rate would also assist in obtaining accurate mortality statistics for epidemiology and research (Alderson et al., 1983).

It is important to remember that for the clinician to obtain the maximum information from an autopsy the pathologist must also play his part to ensure that the autopsy is properly performed. The demonstration and discussion of the findings offers a unique opportunity for both undergraduate and postgraduate education and is an important part of a pathologist's duty. If it is not possible to hold such a conference on every case it is particularly important that the postmortem report is adequate, discussive and reaches the clinician within $24 \mathrm{~h}$.

Such availability of autopsy findings provides a major contribution to medical audit. Clinicians who wish to remain fully aware of their own diagnostic performance should be eager to ensure that postmortem examination is the rule rather than the exception.

\section{Acknowledgements}

We should like to thank the many clinicians at the Leiceste8 Royal Infirmary who co-operated in this survey and Mrs GO Holmes, who typed the manuscript.

CAMERON, H.M., MCGOOGAN, E. \& WATSON, H. (1980). Necropsy, a yardstick for clinical diagnoses. British Medical Journal, 281, 985.

McGOOGAN, E. \& CAMERON, H.M. (1978). Clinical attitudes to the autopsy. Scottish Medical Journal, 23, 19.

ROBINSON, M.J. (1983). The autopsy, 1983: can it be revived? Human Pathology, 14, 566.

SANDRITTER, W., STAENDINGER, M. \& DREXLER, H. (1980). Autopsy and clinical diagnosis. Pathology $R e-$ search and Practice, 168, 107.

THURLBECK, W.M. (1981). Accuracy of clinical diagnosis in a Canadian teaching hospital. Canadian Medical Association Journal, 125, 443. 